\title{
PEMBERDAYAAN KADER DALAM UPAYA PENINGKATAN CAKUPAN DETEKSI DINI KANKER SERVIKS DAN KANKER PAYUDARA, DI DESA CIKUNIR 2018
}

\section{OLEH :}

\author{
Widya Maya Ningrum, SST, \\ M.Kes \\ (widyamayaningrum@gmail.com) \\ Fenty Agustini, SST, M.Kes \\ (fenty.nabiq@yahoo.com) \\ Lilis Lisnawati, SST, M.Keb \\ (aura8277@yahoo.co.id)
}

\section{A. DASAR PEMIKIRAN}

Kanker adalah terjadinya pertumbuhan sel tidak terkontrol sehingga ditemukan sel tubuh yang abnormal (sel kanker). Menurut Globacan, pada tahun 2008 kanker yang paling sering terjadi pada wanita adalah kanker payudara dan kanker serviks. Setiap tahun kanker payudara mencapai 1.1 juta perempuan dan jumlah ini merupakan $10 \%$ dari kasus baru seluruh kanker. Dengan angka kematian sebesar 410.000 setiap tahun dan menjadikan lebih dari 1,6\% sebagai penyebab kematian perempuan di seluruh dunia.

Kanker serviks menempati urutan yang kedua setelah kanker payudara. Kejadian kanker serviks 15 per 100.000 wanita dan 7,8 persen nya mengalami kematian. (Globocan, 2012). Kanker serviks masih menjadi permasalahan kesehatan dengan kejadian kematian tertinggi. Keterlambatan dalam mendiagnosis menyebabkan kanker sudah pada stadium lanjut, dan hal ini merupakan salah satu penyebab tidak tertanganinya kanker serviks.

Sebanyak 99,7 \% penyebab kanker serviks adalah Human Paviloma Virus Onkogenik, dan yang menjadi faktor risikonya adalah Menikah Muda ( $<20$ tahun $)$, Mitra seksual multiple, Infeksi Menular Seksual, Merokok, Defisiensi Vit A./Vit C/VitE (Kemenkes, 2016). Sebanyak 50 - 80\% wanita aktif seksual mengalami infeksi HPV dalam hidupnya tanpa disadarinya, tetapi $90 \%$ hilang dengan daya tahan tubuh. Untuk itu sebenarnya kanker serviks dapat dicegah. Pencegahan yang dapat dilakukan terhadap kanker serviks adalah pencegahan primer dan sekunder. Pencegahan primer dilakukan pada perempuan yang sehat yang belum terkena suatu penyakit. Contoh pencegahan primer untuk kanker serviks adalah dengan melakukan promosi dan edukasi atau kampanye kanker serviks dalam rangka meningkatkan pengetahuan masyarakat tentang kanker serviks serta Vaksinasi HPV untuk mencegah perempuan dari kanker serviks. Pencegahan sekunder adalah dengan cara melakukan deteksi dini dengan melakukan pemeriksaan pap smear dan atau iva test. (National Cancer Institute, 2017)

Tidak seperti kanker serviks yang dapat diketahui etiologi dan perjalanan penyakitnya secara jelas, etiologi dan perjalanan penyakit kanker payudara terutama berhubungan dengan keadaan hormonal (estrogen dominan) dan genetik. Untuk mengatasi masalah pada kanker payudara, maka dikebangkan tatacara deteksi dini dan diagnosis serta penatalaksnaaan yang "cost effective" dengan "evidence based best practies wuth limited resources". Hal dapat dilakukan untuk mencegah terjadinya kanker payudara adalah dengan cara melakukan 
SADARI (Periksa Payudara Sendiri) yang dilakukan rutin setelah menstruasi, selanjutnya setahun sekali dianjurkan untuk SADANIS (periksa Payudara Klinis) yang dilakukan oleh tenaga medis yang kompeten. Selain itu deteksi dini bisa dilakukan dengan cara Mammografi, USG, dll.(Kemenkes, 2016)

Masih rendahnya pengetahuan masyarakat tentang pentingnya pencegahan kanker payudara dan kanker serviks sebagai salah satu faktor penyebab rendahnya cakupan deteksi dini di wilayah Desa Cikunir. Berdasarkan Laporan Profil Kesehatan Dinas Kesehatan Kabupaten Tasikmalaya Tahun 2017 didapatkan data cakupan deteksi kanker payudara dan kanker serviks di Desa Cikunir sebesar 0, 00 \%. Hal ini menunjukan bahwa kesadaran wanita usia subur untuk melakukan pemeriksaan deteksi dini kanker payudara dan serviks sangatlah rendah. Sejalan dengan hasil survey yang dilakukan pada 20 wanita usia subur, sebagian besar pengetahuan wus tentang kanker payudara dan kanker serviks sangatlah kurang, dan semua WUS yang dilakukan survey belum pernah melakukan pemeriksaan deteksi dini kanker payudara dan kanekr serviks.( Laporan PKN, 2018)

Agar pengetahuan perempuan tentang kanker payudara dan kanker serviks dan perilaku deteksi dini meningkat yang berdampak kepada tercapainya cakupan deteksi dini kanker payudaradan kanker serviks maka perlu dilakukan suatu program pemberdayaan masyarakat dengan membentuk Komuitas Kader Peduli Kanker (KKPK). KKPK ini dibentuk dengan tujuan agar dapat meningkatkan kepedulian masyarakat khususnya perempuan terhadap pentingnya pencegahan kanker payudara dan kanker serviks. Dengan $K K P K$ diharapkan pengetahuan masyarakat akan kanker payudara dan serviks meningkat yang berdampak kepada peningkatan kepedulian untuk melakukan deteksi pencegahan kanker payudara dan kanker serviks. Untuk lebih jelasnya dalam laporan ini akan dijelaskan kegiatan - kegiatan yang telah dilakukan dalam rangka Pemberdayaan Kader Dalam Upaya Peningkatan Cakupan Deteksi Dini Kanker Serviks Dan Kanker Payudara Di Desa Cikunir 2018.

\section{B. TUJUAN KEGIATAN}

Kegiatan ini bertujuan untuk :

1. Membentukan Komunitas Kader Peduli Kanker

2. Melaksanakan Pelatihan kader peduli kanker

3. Melaksanakan bakti sosial Pemeriksaan deteksi dini kanker payudara dan serviks.

\section{SASARAN}

Dalam kegiatan ini sasaran kegiatan adalah kader peduli kanker di satu Desa Cikunir yang diwakili oleh kader dari masing masing RW.

Selain itu sasaran dalam pemeriksaa dini kanker payudara yang serviks adalah wanita usia subur di Desa Cikunir Kecamatan Singaparna Kabupaten Tasikmalaya

\section{WAKTU DAN TEMPAT PELAKSANAAN}

Kegiatan dilaksanakan pada bulan September s/d Oktober 2018 di STIKes Respati Tasikmalaya 


\section{E. HASIL KEGIATAN}

\section{Pembentukan Komunitas Kader Peduli Kanker.}

Rangkaian kegiatan Pemberdayaan Kader Dalam Upaya Peningkatan Cakupan Deteksi Dini Kanker Serviks Dan Kanker Payudara Di Desa Cikunir 2018 diawali dengan perekrutan anggota komunitas, dengan melibatkan bidan desa, kepala desa, bidan koordinator Puskesmas Singaparna. Pada tanggal 24 September perekrutan dilakukan dengan sukarela, dan terbentuklah 15 orang kader perwakilan tiap RW yang bersedia untuk mengikuti rangkaian kegiatan yang akan dilakukan. Adapun nama kader yang terekrut adalah:

a. RW 01 : SitiNurjanah

b. RW 02 : Elli Emalia

c. RW 03 :Sukmirah

d. RW 04 : Desi Ratnasari

e. RW 05 : Ratmi Sari Ningsih

f. RW 06 : Evi Sopiah

g. RW 07 : Wida Novia Asmara

h. RW 08 : Evi

i. RW 09 : Yunita Rosliana

j. RW 10 : Enung Nurjanah

k. RW 11 : Nia Kurniawati

1. RW 12 : Rita Sri Purwita

m. RW 13 : N Heryanan

n. RW 14 : Enung Listiani

o. RW 15 : Fitri Purnamasari

Secara kelompok kumpulan kader ini diberi nama Komunitas Kader Peduli Kanker yang kemudian dapat disingkat KKPK, dan apabila sebagai individu yang melakukan Komunikasi, Informasi dan edukasi kepada masyarakat, peran mereka sebagai Duta Kanker.

2. Pelatihan untuk Komunitas Kader Peduli Kanker

Pelatihan kader ini dilaksanakan pada tanggal 2-3 Oktober 2018 bertempat di STIKes Respati Tasikmalaya. Dengan sasaran pelatihan adalah KKPK sebanyak 15 orang kader yang terpilih. Adapun rangkaian kegiatan yang dilalui dalam pelatihan ini adalah:

a. Pembukaan pelatihan

Pembukaan dihadiri oleh ketua STIKes Respati Tasikamalaya, Kepala Des Cikunir, Kepala Puskesmas Singaparna, Bidan Desa Cikunir, KKPK, Panita Dosen dan mahasiswa, narasumber. (daftar hadir terlampir). Bapak kepala desa sangat menyambut program ini dengan dibentuknya KKPK diharapkan masyarakat akan lebih peduli terhadap kesehatan reproduksinya. Dan bapak kepala desa menyatakan dukungannya, dengan dialokasikannya dana untuk kegiatan ini. Acara pembukaan ini dibuka oleh bapak Kepala Puskesmas Singaparna. 
b. Pelatihan hari ke -1

Kegiatan pelatihan di hari ke -1 diawali dengan kegaiatan perkenalan dari para peserta. Perkenalan dilakukan dengan cara memperkenalkan diri sendiri dengan menyebutkan nama dan hobi dari masing - masing peserta. Setelah perkenalan selesai peserta pelatihan menuliskan harapan selama kegiatan ini berlangsung, dan menyekapati tata tertib ujian . selanjutnya gambaran umum pelatihan yang disampaikan oleh Hapi Apriasih, SST, M.Kes. gabaran umum pelatihan ini disampaikan dengan tujuan untuk memberikan gambaran kepada peserta, selama pelatihan ini apa saja yang akan diterima dan dilalui, dengan harapan peserta akan mengukuti kegiatan ini tanpa ada kecuali.

Dilanjutkan dengan pre test, dengan hasil:

Hasil pre test peserta pelatihan kader peduli kanker

\begin{tabular}{|c|l|c|}
\hline No & \multicolumn{1}{|c|}{ Nama } & Nilai Pre test \\
\hline 1. & Lina & 66,7 \\
\hline 2. & Desi Ratnasari & 73,3 \\
\hline 3. & Milah J & 53,3 \\
\hline 4. & Evi S & 53,3 \\
\hline 5. & Nia Kurniawati & 53,3 \\
\hline 6. & Sukmirah & 66,7 \\
\hline 7. & Enung Nurjanah & 46,7 \\
\hline 8. & N Heryanah & 60 \\
\hline 9. & Fitri & 80 \\
\hline 10. & Siti Nurjanah & 66,7 \\
\hline 11. & Elli Emalia & 73,3 \\
\hline 12. & Rita Sri P & 73,3 \\
\hline 13. & Enung Listiani & 60 \\
\hline 14. & Wida Novia & 55,7 \\
\hline 15. & Ratmi SN & 73,3 \\
\hline
\end{tabular}

Rata - rata pre test 63,70 dengan nilai terendah 46,7 dan nilai tertinggi 80.

Setelah pre test, dilanjutkan dengan materi pertama dengan topic pengertian penyakit kanker secara umum yang disampaiakn oleh Tupriliani Danefi, SST, M.Kes. ,materi ini menjelaskan tentang pemyakit kanker yang sering terjadi pada perempuan, dan menjelaskan secara umum apa yang menajdi penyebab terjadinya kanker pada perempuan. Setelah materi ini selesai paserta Istirahat, Sholat, dan makan selama 60 menit.

Sesi siang dilanjutkan dengan materi deteksi dini kanker leher Rahim yang 
disampaikan oleh Santi Susanti, SST, M.Kes dan Eyi Mulyati, AMd.Keb. Materi ini menjelaksan tentang penyebab, factor resik, pencegahan dan deteksi dini yang harus dilakukan oleh perempuan agar terhindar dari kanker leher Rahim. Dilanjutkan materi tentang deteksi dini kanker payudara, yang disampaiakn oleh Widya Maya Ningrum, SST, M.Kes dan Ina Marlina, STr.Keb Materi ini juga membahas tentang penyebab, faktor risiko, pencegahan dan deteksi dini kanker payudara. Pada sesi ini peserta melakukan praktik SADARI.

Hari pertama ditutup dengan materi KIE tentang kanker leher rahin dan payudara, yang disampaikan oleh Fenty Agustini, SST, M.Kes dan Erwina Sumartini, SST, M.Keb. dalam sesi ini peserta melakukan praktik tentang komunikasi, informasi dan edukasi kepada masayarakat agar masyarakat tau, mau dan mampu melakukan deteksi dini kanker serviks dan payudara.

Berdasarkan hasil evaluasi kegiatan pelatihan hari pertama berjalan lancar, peserta sangat antusias dalam proses, dan kegiatan ini diselingi oleh Ice Breaking yang menyebabkan peserta tidak bosan dalam mengikuti pelatihan.

c. Pelatihan hari ke -2

Pelatihan hari ke-2 diawalai dengan refleksi oleh peserta. Peserta melakukan review terhadap materi yang telah disampaikan di hari pertama. Selanjutnya peserta melakukan post test, berikut hasil post test beserta kenaikan dari nilai pre test dan post test:

\begin{tabular}{|c|l|c|c|c|}
\hline No & \multicolumn{1}{|c|}{ Nama } & Nilai Pre test & Nilai Post Test & Kenaikan Nilai \\
\hline 1. & Lina & 66,7 & 93,3 & 26,6 \\
\hline 2. & Desi Ratnasari & 73,3 & 93,3 & 20 \\
\hline 3. & Milah J & 53,3 & 86,6 & 33,3 \\
\hline 4. & Evi S & 53,3 & 80 & 26,7 \\
\hline 5. & Nia Kurniawati & 53,3 & 86,6 & 33,3 \\
\hline
\end{tabular}




\begin{tabular}{|c|l|c|c|c|}
\hline 6. & Sukmirah & 66,7 & 86,6 & 19,9 \\
\hline 7. & Enung Nurjanah & 46,7 & 80 & 33,3 \\
\hline 8. & N Heryanah & 60 & 63,3 & 13,3 \\
\hline 9. & Fitri & 80 & 93,3 & 13,3 \\
\hline 10. & Siti Nurjanah & 66,7 & 86,6 & 19,9 \\
\hline 11. & Elli Emalia & 73,3 & 86,6 & 13,3 \\
\hline 12. & Rita Sri P & 73,3 & 100 & 26,7 \\
\hline 13. & Enung Listiani & 60 & 73,3 & 13,3 \\
\hline 14. & Wida Novia & 55,7 & 100 & 44,3 \\
\hline 15. & Ratmi SN & 73,3 & 100 & 26,7 \\
\hline
\end{tabular}

Rata - rata nilai post test 87,97 dengan nilai terendah 73,3 dan tertinggi 100 . Kenaikan tertinggi dari nilai pre test ke post test adalah 44,3 .

Setelah post test dilanjutkan dengan assesment untuk teknik KIE. Peserta dibagi menjadi 5 kelompok (jadual terlampir). Adapun hasil assessment yang dilakukan sebagai berikut :

\begin{tabular}{|l|l|c|}
\hline No & \multicolumn{1}{|c|}{ Nama } & Nilai Assesment \\
\hline 1. & Lina & 3,8 \\
\hline 2. & Desi Ratnasari & 3,67 \\
\hline 3. & Milah J & 3,00 \\
\hline 4. & Evi S & 3,15 \\
\hline 5. & Nia Kurniawati & 3,16 \\
\hline 6. & Sukmirah & 3,50 \\
\hline 7. & Enung Nurjanah & 3,00 \\
\hline 8. & N Heryanah & 3,00 \\
\hline 9. & Fitri & 3,83 \\
\hline 10. & Siti Nurjanah & 3,70 \\
\hline 11. & Elli Emalia & 3,83 \\
\hline 12. & Rita Sri P & 3,50 \\
\hline 13. & Enung Listiani & 3,00 \\
\hline 14. & Wida Novia & 3,80 \\
\hline 15. & Ratmi SN & 3,80 \\
\hline
\end{tabular}

Rata - rata nilai praktik adalah 3,45 dengan nilai tertinggi 3,8 dan nilai terendah 3,00.

Setelah assessment peserta melanjutkan dengan rencana tindak lanjut (RTL). Tujuan RTL ini adalah untuk menindaklanjuti hasil pelatihan. Peserta mempunyai jadual untuk selanjutnya melakukan sosialisasi hasil pelatihan. RTL ini sebagai tolak ukur keberlanjutan program. Selaian itu sebagai salah satu bentuk nyata hasil pelatihan in I para duta kanker diwajibkan melakukan rekrut sasaran untuk dapat dilakukan pemeriksaan iva test, pap smear dan SADANIS pada tanggal 6 oktober 2018 . Hasil ini duta kanker mampu merekrut 150 sasaran (RTL dan rerkument sasaran terlampir). Sebagai media yang digunakan untuk proses rekrument, duta kanker dibekali leaflet dan lembar balik. 
d. Penutupan Pelatihan

Pembukaan Penutupan dihadiri oleh wakil ketua STIKes Respati Tasikamalaya, Kepala

Puskesmas Singaparna, Panita Dosen dan mahasiswa, Narasumber. (daftar hadir terlampir). Pada acara penutupan ini diumumkan peserta terbaik atas nama Duta Fitri dan Duta Wida. Penilaian peserta terbaik dilihat dari hasil pre test, post test, assement dan keaktifan pada saat proses.

Pada saat penutupan Ketua pelaksana memberikan laporan hasil evaluasi penyelenggaraaan, dengan hasil sebagai berikut:

\begin{tabular}{|r|l|c|}
\hline No & \multicolumn{1}{|c|}{ Kriteria Penilaian } & Nilai \\
\hline \multirow{2}{*}{1.} & Materi & \\
\cline { 2 - 3 } & a. Kesesuaian dengan tujuan pelatihan & 4,4 \\
\cline { 2 - 3 } & b. Kesesuaian dengan kebutuhan & 4,2 \\
\cline { 2 - 3 } & c. Kualitas & 4,3 \\
\hline 2. & Tempat/fasilitas & 3,03 \\
\hline 3. & Konsumsi & 3,8 \\
\hline 4. & Acara & 3,3 \\
\hline
\end{tabular}

Catatan kategori penilaian 1. Kurang sekali; 2. Kurang; 3. Cukup; 4. Baik; 5. Baik sekali. Hasil evaluasi penyelenggaraan pelatihan dengan kategori Baik - Baik sekali. Hasil ini bias dijadikan tolak ukur untuk penyelenggaraan kegiatan selanjutnya. (hasil terlampir) Selain evaluasi penyelenggaraan, ketua pelaksana pun melaporkan evaluasi narasumber, berikut hasilnya:

\begin{tabular}{|r|l|c|c|c|c|c|c|c|}
\hline \multirow{2}{*}{ NO } & \multirow{2}{*}{ NAMA } & \multicolumn{7}{|c|}{ PENILAIAN } \\
\cline { 3 - 9 } & & Penguasaan & Cara & Sistematika & Partisipatif & Kedekatan & Penampilan & Total \\
\hline 1 & Hapi Apriasih & 71 & 68 & 64 & 66 & 66 & 69 & 404 \\
\hline 2 & Tupriliany Danefi & 72 & 69 & 65 & 66 & 68 & 69 & 409 \\
\hline 3 & Santi Susanti & 72 & 70 & 66 & 67 & 68 & 70 & 413 \\
\hline 4 & Widya Maya & 73 & 72 & 71 & 71 & 72 & 72 & 431 \\
\hline 5 & Erwina Sumartini & 72 & 65 & 64 & 65 & 69 & 71 & 406 \\
\hline 6 & Fenty Agustini & 72 & 67 & 65 & 65 & 68 & 71 & 408 \\
\hline
\end{tabular}

Dalam penyelenggaraan pelatihan ini peserta memberikan saran, yaitu:

1) Acara diadakan rutin

2) Untuk konsumsi tidak ada buah - buahan

3) Adakan acara dengan topik yang lain.

4) Bahasa harus yang dimengerti oleh kader

Dalam acara penutupan ini, para kader membacakan fakta integritas, sebagai bentuk komitmen pada duta kanker dalam menajalankan tugasnya kedepan. Dan diakhir dengan penandatanagana fakta intergitas oleh seluruh peserta yang hadir. (terlampir) 
3. Pemeriksaan deteksi dini kanker payudara dan serviks.

Sebagai tindak lanjut dari pembentukan KKPK dan pelatihan, maka sebagai tolak ukur keberhasilan program adalah terekrutnya sasaran dalam hal ini wanita usia subur di wilayah Desa Cikunir untuk melakukan deteksi dini kanker serviks dan kanker leher Rahim. Dari hasil kerja KKPK didapatkan sasaran 150 orang. Kegiatan ini bekerja sama dengan Yayasan Kanker Indonesia Cabang Kabupaten Tasikmalaya, Prodia dan RSIA Respati.

Kegiatan pemeriksaan IVA Test, Pap smear dan SADANIS dilakukan di RSIA Respati pada hari Sabtu, 6 Oktober 2018. Adapun laporan pelaksanaan kegiatannya sebagai berikut:

a. Pembukaan

Pembukaan acara dilakukan di Aula Graha Respati, yang dihadiri oleh pengurus YKI, Karyawan RSIA, Karyawan dan Dosen STIKes Respati TAsikmalaya, mahasiswa program studi kebidanan, mahasiswa program studi kesehatan masyarakat, KKPK, kader desa cikunir, dan masyarakat umum dari kecamatan Singaparna. Acara dibuka oleh Ketua YKI Cabang Kabupaten Tasikmalaya, dr.Polar Silumi, SpOG, MH.Kes (Susunan acara terlampir)

b. Diskusi interaktif

Setelah pembukaan acara dilanjutkan dengan diskusi interaktif dengan 3 narasumber

1) dr. Aa Ahmad Dimyati, Sp. B, MM.Kes dengan topic deteksi dini kanker payudara dan berlaku sebagai moderator dr. Iman Firmansyah.

2) dr. Polar Silumi, SpOG, MH.Kes dengan topic deteksi dini kanker serviks dan berlaku sebagai moderator dr. Aa Ahmad

3) dr. Ketut Suhendro, M.Kes, AIFO SpOG, dengan topic penanganan terapy pra kanker dan berlaku sebagai moderator dr. Anas Kalyubi.

Kegiatan diskusi interaktif ini dihadiri oleh 300 orang (daftar hadir terlampir)

c. Pemeriksaan deteksi dini kanker serviks dan kanker payudara

Kegiatan pemeriksaan IVA test, pap smear dan sadanis dilakukan di RSIA Respati, jumlah sasaran yang diperiksa menjadi 86 orang dari 150 sasaran yang terekrut dengan berbagai alasan:

1) Sedang menstruasi

2) Post coitus

3) Sedang hamil

4) Dll.

Sasaran yang dilakukan pemeriksaan adalah sasaran yang mempunyai BPJS. Pemeriksaan dilakukan langsung oleh pihak prodia. Terdapat sasaran umum dilakukan pemeriksaan oleh 
YKI sejumlah 3 orang dengan pembayaran 150.000 per orang.

Untuk hasil pemeriksaan pap smear akan diperoleh 3 minggu paska pengambilan hapusan, dengan alur : hasil pemeriksaan akan diserahkan ke puskesmas Singaparna, dibantu oleh KKPK pihak puskesmas akan menyebarkan hasil pemeriksaan kepada sasaran. Selanjutnya bagi hasil yang terdeteksi mengalami kelainan maka akan langsung dirujuk untuk pemeriksaan dan konsultasi lebih lanjut kepada pihak YKI.

Untuk Iva test didapatkan hasil 8 orang positif, bagi sasaran yeng teridentifikasi positif, dianjurkan untuk konsultasi dan pemeriksaan lebih lanjut ke pihak YKI. Dan 1 orang teridentifikasi terdapat benjolan di payudara. Ditindaklanjuti dengan pemberian voucer pemeriksaan gratis ke specialist bedah yang praktik di RSIA. (hasil pemeriksaan terlampir)

\section{F. DAFTAR PUSTAKA}

Globocan 2012 (IARC), Cervical Cancer, Estimated Incidence, Mortality And Prevalence Worldwide In 2012. Section Of Cancer Surveillance. 2012

Kementrian Kesehatan RI., 2016., Buku Acuan Pencegahan Kanker Payudara Dan Kanker Leher Rahim, Direktorat Jendral Pencegahan Dan Pengendalian Penyakit Tidak Menular

Profil Dinas Kesehatan Kabupaten Tasiknalaya, 2017

National Cancer Institute. (2017). Human Papillomavirus (HPV) Vaccines 


\section{G. DOKUMENTASI}
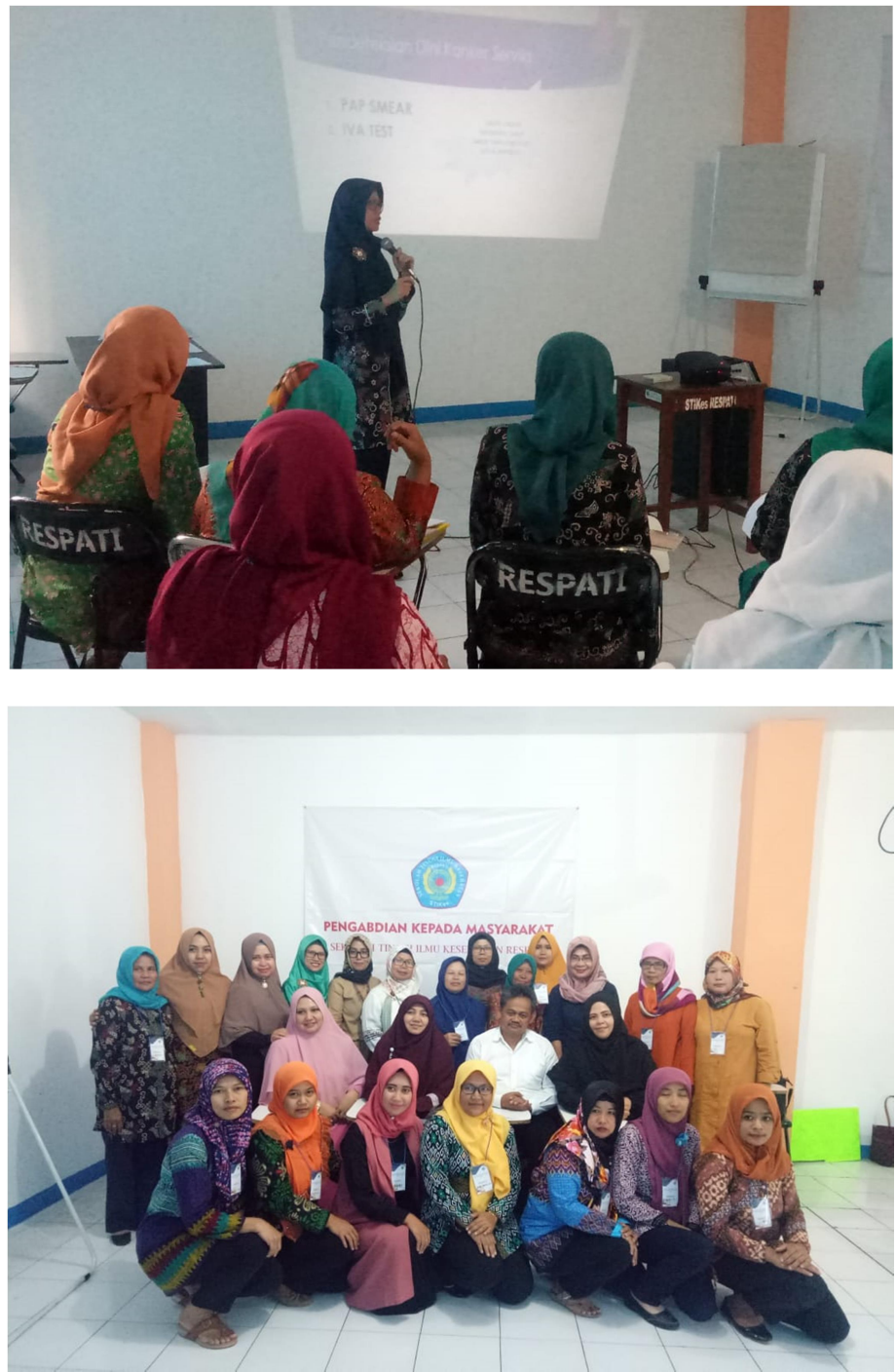